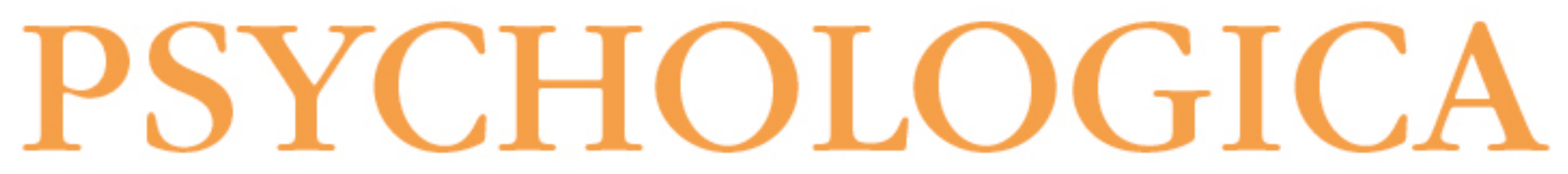

Vinculação a pais, pares e professores: estudos com o IPPA-R para crianças do ensino básico

Autor(es): $\quad$ Machado, Teresa Sousa; Figueiredo, Tânia

Publicado por: Imprensa da Universidade de Coimbra

URL

persistente: URI:http://hdl.handle.net/10316.2/5534

DOI: DOI:http://dx.doi.org/10.14195/1647-8606_53_2

Accessed : $\quad$ 26-Apr-2023 11:26:41

A navegação consulta e descarregamento dos títulos inseridos nas Bibliotecas Digitais UC Digitalis, UC Pombalina e UC Impactum, pressupõem a aceitação plena e sem reservas dos Termos e Condições de Uso destas Bibliotecas Digitais, disponíveis em https://digitalis.uc.pt/pt-pt/termos.

Conforme exposto nos referidos Termos e Condições de Uso, o descarregamento de títulos de acesso restrito requer uma licença válida de autorização devendo o utilizador aceder ao(s) documento(s) a partir de um endereço de IP da instituição detentora da supramencionada licença.

Ao utilizador é apenas permitido o descarregamento para uso pessoal, pelo que o emprego do(s) título(s) descarregado(s) para outro fim, designadamente comercial, carece de autorização do respetivo autor ou editor da obra.

Na medida em que todas as obras da UC Digitalis se encontram protegidas pelo Código do Direito de Autor e Direitos Conexos e demais legislação aplicável, toda a cópia, parcial ou total, deste documento, nos casos em que é legalmente admitida, deverá conter ou fazer-se acompanhar por este aviso. 
NÚMERO 53

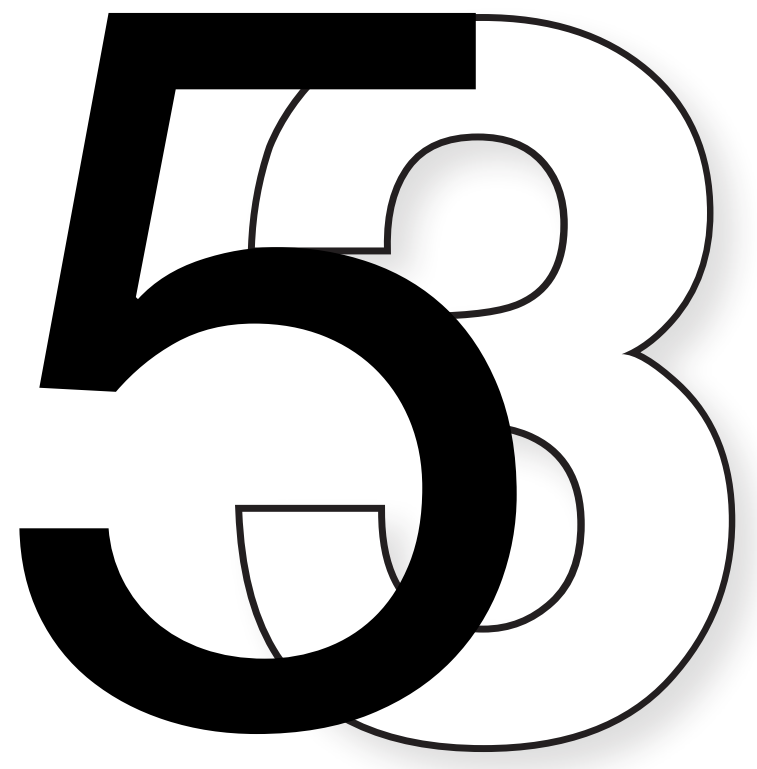

IMPRENSA DA UNIVERSIDADE DE COIMBRA

FACULDADE DE PSICOLOGIA E DE CIÊNCIAS DA EDUCAÇÃO DA UNIVERSIDADE DE COIMBRA 


\title{
Vinculação a Pais, Pares e Professores - estudos com o IPPA-R para crianças do ensino básico
}

\begin{abstract}
Teresa Sousa Machado' \& Tânia Figueiredo²
O período do meio da infância - período de latência - tem sido menos investido no âmbito dos estudos da vinculação. Todavia, tarefas normativas como a adaptação escolar são essenciais para o desenvolvimento nestas idades e parecem exigir competências psicossociais que são influenciadas pela vinculação aos cuidadores principais. Na escola, pares e professores podem também assumir papéis significativos - complementares aos pais - funcionando aí como ponto de referência ou apoio. $O$ presente trabalho apresenta dados preliminares da adaptação e validação de três versões - Pais, Pares e Professores - do IPPA-R (Inventory of Parent and Peer Attachment, de Armsden \& Greenberg), a crianças entre os 9 e 11 anos. Os três instrumentos de auto-relato - cada um com 25 itens - passados a uma amostra de 254 crianças do ensino Público e Privado/cooperativo, apresentam estrutura factorial semelhante entre si, composta por três sub-escalas. As qualidades psicométricas encontradas e a facilidade de aplicação sugerem que se tratam de instrumentos adequados para avaliar a segurança da relação a figuras significativas nestas idades.
\end{abstract}

PALAVRAS-CHAVE: vinculação, IPPA (Pais, Pares, Professores), crianças

\section{Introdução}

Vincular-se a alguém constitui um processo vital, desde o início da vida, e a possibilidade de manter uma vinculação segura ao longo do desenvolvimento, particularmente nos primeiros anos, forma alicerces para uma representação de si como digno de apreço, e do mundo como suficientemente seguro para nele se poder lançar. Na infância as relações pais-filhos são o contexto da construção da vinculação sendo esta encarada em termos relacionais; no adulto, a segurança é vista já como uma característica da pessoa (Thompson, 2008). A teoria da vinculação procura compreender de que modo - ao longo do desenvolvimento - as facetas das relações significativas são incorporadas na personalidade.

\footnotetext{
1 Faculdade de Psicologia e Ciências da Educação - Universidade de Coimbra - tmachado@fpce.uc.pt

2 Colégio Nossa Senhora da Assunção - Anadia;
} 
É a partir das rotinas relacionais com uma figura que se torna progressivamente significativa que o bebé vai construindo expectativas de como será tratado e de como influencia o outro (despoletando-lhe respostas) (Bowlby, 1984/1964); expectativas que sedimentam as representações que se organizam segundo modelos internos dinâmicos do selfe das relações (Cassidy, Scolton, Krisk, \& Parke, 1996). Nos termos de Bowlby (1956), da dependência fundamental inicial constrói-se a independência necessária para um funcionamento equilibrado, para além das fronteiras do lar (i.e. para além das relações primárias). Noutros contextos significativos (e.g. creche ou escola), outras tarefas desenvolvimentais serão melhor conseguidas quando o sujeito dispõe de recursos psicológicos que o capacitam para se "abrir ao exterior", sem contudo perder a sua individualidade. Se considerarmos cada novo contexto relacional como uma nova Situação Estranha (metaforicamente referindo-nos ao paradigma de observação criado por Ainsworth), o ingresso numa nova fase de estudos, pelas exigências que coloca, exige readaptações que o sujeito mais flexível (i.e. o seguro) consegue facilmente enfrentar. Apresentamos neste trabalho as análises de três versões (Pais, Pares e Professores) da escala de vinculação IPPA-R (Inventory of Parent and Peer Attachment), para crianças entre os 9 e 11 anos. Estes instrumentos, para além das representações aos Pais, permitem avaliar a qualidade da representação aos Pares e Professores (figuras que se podem assumir como significativas em contexto escolar).

\section{Vinculação ao longo da infância}

Bowlby encontrou na etologia bases que justificam o carácter de necessidade da vinculação e, correlativamente, dos comportamentos e expressões de emoções que fazem parte do repertório do recém-nascido e que desencadeiam - naturalmente - as respostas do cuidador (Grossmann, Grossmann \& Waters, 2005; Rholes \& Simpson, 2004). Ao longo do primeiro ano, os cuidadores primários tornar-se-ão progressivamente diferenciados (i.e. individualizados) na mente da criança - o desenvolvimento da capacidade de representação permitindo o que Piaget designa de "interiorização da acção" (Bretherton, 2005; Piaget, 1986). Neste sentido, reforça-se a tese de Bowlby de que as representações construídas derivam de "experiências reais" da vida (o que o levará, aliás, a questionar um dos fundamentos da sua formação psicanalítica: a preponderância da fantasia no desenvolvimento da psicopatologia) (in Machado, 2009).

Ao longo da infância a qualidade da comunicação, no contexto das relações de vinculação, continua a influenciar a (in)segurança da criança e eventuais ameaças à disponibilidade e responsividade do cuidador podem predispor à perturbação 
(Gullone, Ollendick, \& King, 2006; Koback \& Madsen, 2008). Por outro lado, a sensibilidade das figuras de vinculação ao alargamento progressivo da exploração e "afastamento" dos filhos, parece ser tão significativa para o desenvolvimento da autonomia, como a sensibilidade manifestada no anterior período de desenvolvimento (Bowlby, 1998/1973; Grossmann, Grossmann, \& Kindler, 2005).

Muito cedo se podem observar diferenças interindividuais nos padrões de vinculação (Ainsworth, Blehar, \& Wall, 1978), e tais diferenças contribuem, conjuntamente com outros factores, para a adaptação da criança a novos ambientes. Se os padrões seguros favorecem a separação (estas crianças sabem que podem sempre reencontrar o cuidador, se necessitarem) possibilitando maior investimento cognitivo em novas explorações; favorecem também a resolução de problemas ou conflitos sociais (e.g. entre pares), uma vez que se trata aqui de crianças que aprenderam estratégias adaptativas de negociação. Quanto às crianças inseguras, a mudança para novos ambientes (como, e.g., o $5^{\circ}$ ano, em Portugal), ao (re)activar o sistema de vinculação, pode desencadear as (anteriores) estratégias de lidar a ansiedade. Ou seja, os inseguros ansiosos/ambivalentes tendem a aumentar expressões de necessidade/angústia na ânsia de captar atenções (Karen, 1998); enquanto que os inseguros evitantes (num movimento imediato) tenderão a minimizar a necessidade de outro, afastando novos pares (ou professores) (Machado, 2007; 2009). Se, para estas crianças inseguras, tais estratégias são adaptativas na relação com a(s) figura(s) principais de vinculação, elas não o serão, forçosamente, no meio escolar. De facto, diversos estudos têm confirmado estas tendências da transposição para as novas relações, das estratégias construídas no seio das relações primárias (cf., e.g., in Soares, Martins \& Tereno, 2007; Mendonça, Cossette, Lapointe, \& Strayer, 2008). Assim, a capacidade de lidar a distância da figura de vinculação pode ser vista como uma tarefa desenvolvimental (Machado, 2007), passando a escolarização bem conseguida por esse distanciamento (Bowlby, 1998; Grossmann, Grossmann, \& Kindler, 2005; Strecht, 2008). Nos anos do meio da infância não será já a resposta à separação que traduz a qualidade da vinculação, mas os comportamentos face a outros e novas situações, pelo que traduzem das expectativas que orientam as acções das crianças.

Tem também sido sugerido que a relação entre a vinculação e as relações com os pares é mais forte para crianças de idade escolar e adolescentes do que para crianças mais novas (Thompson, 2008); o que pode ser interpretado com base na maior sofisticação e consolidação das representações de relações de amizade ao longo do desenvolvimento. Com efeito, ao longo da escolaridade básica, os pares assumem maior papel nas relações e tornam-se parceiros preferidos para brincadeiras. Para tal contribuem também as alterações na supervisão parental que passa, ao longo do meio da infância, da preponderância do controlo parental 
para a co-regulação com a criança (Kerns, 2008; Thompson, 2008). Alguns autores referem todavia que os pares não servem verdadeiramente como "figuras de vinculação" em momentos de necessidade/tristeza na infância (Kerns, 2008); porém, tal não significa que as crianças não dirijam, por vezes, comportamentos de vinculação aos pares, particularmente quando as figuras parentais estão indisponiveis (Kerns, 2008) - movimento interpretado como uma transição desenvolvimental das figuras primárias para figuras secundárias de vinculação (Mayseless, 2005).

A regulação emocional torna-se progressivamente capacidade da criança, que se torna mais auto-suficiente na regulação dos seus comportamentos (Bradley, 2003) - i.e., se pôde interiorizar, porque as vivenciou, estratégias adequadas e compreende que eventuais emoções negativas não são forçosamente destrutivas ou aniquiladoras, podendo ter "resolução" satisfatória: "O cuidador suficientemente bom é o que não fica agitado ou desorganizado pela expressão de uma forte emoção do seu filho, mas, pelo contrário, é capaz de aceitar as expressões emotivas da criança e simultaneamente modelar novas formas de as expressar" (Greenberg, Kusche, \& Speltz, 1991, p.27).

A longo prazo, a eventual continuidade na qualidade das vinculações ultrapassa a influência mais directa das relações familiares e passa a incorporar, progressivamente, as confirmações de outros significativos (e.g. pares e professores) (Machado, 2007); podendo ocorrer reestruturações nos modelos internos se o meio exterior "refutar" sistematicamente a imagem que a criança havia construído (e.g. a criança "desinteressante" para o cuidador pode ser "atraente" para os colegas e professores). Para o meio da infância as crianças terão desenvolvido um modelo mais geral das relações das vinculação - um "estado mental relativo à vinculação", nas palavras de Main, Kaplan e Cassidy (in Kerns, 2008). Este estado mental geral afina-se ao longo do final da infância, sofisticando-se na adolescência com o desenvolvimento do raciocínio formal e um maior alargamento dos horizontes relacionais e maior investimento afectivo nos pares (Allen \& Land, 1999). Acredita-se que no final da infância, algumas crianças desenvolveram já uma representação interna geral e consistente das relações de vinculação, isto, particularmente, naquelas cujas experiências prévias com diferentes figuras de vinculação foram consistentes (Kerns, 2008). Esta tarefa desenvolvimental pode não ser conseguida tão cedo para as que enfrentam o difícil processo de integração de experiências relacionais muito diversas (Kerns, 2008).

A escolaridade bem conseguida, ou pelo contrário, o abandono escolar, devem, nesta óptica, ser encarados como processos desenvolvimentais a longo prazo (Marcus \& Sanders-Reio, 2001; Strecht, 2008) - embora muitos pais ou professores se centrem apenas num resultado quantitativo final. Faz todo o sentido enquadrar o sucesso ou fracasso escolar num percurso de desenvolvimento e uma das variáveis 
a considerar pode ser, de facto, a influência que a qualidade dos modelos internos dinâmicos transporta para as relações a construir neste contexto. Propomos assim, neste trabalho, análises de três versões (Pais, Pares e Professores) da escala de vinculação IPPA-R (Inventory of Parent and Peer Attachment), para crianças entre os 9 e 11 anos. A versão para professores foi construída neste presente estudo- não existindo na versão original de Armsden e Greenberg (1987), nem nas versões Pais e Pares, para crianças, de Gullone e Robinson (2005). Considerando o papel que o Professor pode assumir como figura influente no desenvolvimento e bem-estar da criança, será pertinente dispor de um instrumento que analise a forma como estas avaliam tal relação.

\section{Método}

\subsection{Amostra}

A amostra, seleccionada por método não probabilístico por conveniência, é constituída por 254 alunos de escolas do ensino público e particular/cooperativo, dos distritos de Aveiro (45\%) e Viseu (55\%), com idades entre os 9-11 anos, sendo que $25 \%$ tem 9 anos, $61 \%$ tem 10 anos e $14 \%$ tem 11 anos. A maioria frequenta o $5^{\circ}$ ano $(76.4 \%)$. A média de idades é de 9.89 anos ( $D P=0.62$ ), sendo 150 raparigas (59.1\%) e 104 rapazes (41\%).

Os critérios de inclusão foram possuir nacionalidade portuguesa, ter entre $9 \mathrm{e}$ 11 anos, aptidão para a leitura e escrita autónoma. Como critério de exclusão considerou-se serem alunos referenciados com deficiência mental ou algum tipo de necessidade educativa especial que dificultasse a compreensão e/ou preenchimento dos questionários.

\subsection{Instrumentos}

IPPA-R - Escala de Vinculação aos Pais (Figueiredo \& Machado, 2008)

As versões IPPA-R (Pais, Pares e Professores), aqui apresentadas, foram construídas a partir das versões IPPA-R (Pais e Pares) de Armsden e Greenberg (1987). São instrumentos de auto-avaliação, sendo cada uma das três versões constituídas por 25 itens. As análises factoriais realizadas levaram (à semelhança dos instrumentos originais) à distinção de três sub-escalas que designámos de Comunicação e Proximidade Afectiva, avaliando a qualidade da comunicação e sentimento de 
proximidade aos Pais (e.g. "Os meus pais ajudam-me a falar nas minhas preocupações", "Eu conto aos meus pais os meus problemas e preocupações"); Aceitação mútua e Compreensão, avaliando a percepção de aceitação mútua e capacidade de compreensão (e.g. "Penso que os pais são uns bons pais", "Os meus pais aceitam-se tal como sou"); e Afastamento e Rejeição, avaliando o sentimento de afastamento afectivo e rejeição que as crianças percepcionam relativamente às figuras parentais (e.g. "Os meus pais não entendem o que estou a passar agora"). Embora as três versões: Pais, Pares e Professores sejam constituidas pelas mesmas dimensões, os itens que as compõem não são sempre os mesmos (dado o diferente peso factorial obtido). As respostas organizam-se numa escala tipo Lickert de 5 pontos: de "Sempre verdadeira" (5 pontos) a "Muitas vezes verdadeira", "Algumas vezes verdadeira", "Poucas vezes verdadeira" e "Nunca verdadeira" (1ponto); sendo que alguns itens têm a cotação invertida. A pontuação total é obtida através da soma das dimensões Comunicação $e$ Proximidade Afectiva e Aceitação mútua e Compreensão e subtracção do total da dimensão Afastamento e Rejeição. O instrumento avalia a segurança/insegurança percepcionada na relação com os pais.

IPPA-R - Escala de Vinculação aos Pares (Figueiredo \& Machado, 2008)

A versão Pares é composta igualmente por 25 itens que avaliam a representação da qualidade da vinculação, neste caso aos pares. As três sub-escalas correspondentes às três dimensões, Comunicação e Proximidade Afectiva, Aceitação Mútua e Compreensão, e a dimensão Afastamento e Rejeição, referem-se agora às relações com os pares que se assumem como amigos: e.g., "Os meus amigos ajudam-me a compreender-me melhor" - Comunicação e Proximidade Afectiva; "Eu confio nos meus amigos" - Aceitação mútua e Compreensão; "Parece-me que os meus amigos estão zangados comigo sem razão" - Afastamento e Rejeição. A cotação segue os mesmos critérios da versão Pais.

\section{IPPA-R - Escala de Vinculação aos Professores (Figueiredo \& Machado, 2008)}

A versão Professores, construída para o presente estudo, segue uma estrutura similar às versões Pais e Pares - ou seja, 25 itens que avaliam a percepção da qualidade da relação construída com professores significativos, itens que se podem organizar nas três dimensões citadas. Assim, a Comunicação e Proximidade Afectiva pode ser avaliada por itens como, e.g. "Os meus professores ajudam-me a falar das minhas preocupações", ou "Eu posso contar com os meus professores quando preciso de desabafar"; a Aceitação Mútua e Compreensão em frases como, e.g., "Eu confio nos meus professores", ou (item invertido) "Irrito-me facilmente com os meus professores"; e a dimensão Afastamento e Rejeição traduzida, e.g., em 
frases como "Os meus professores não entendem o que estou a passar agora", ou "Eu não recebo muita atenção dos meus professores". A cotação segue os mesmos critérios das versões Pais e Pares.

\subsection{Procedimentos}

O processo de adaptação das escalas iniciou-se com o contacto com as autoras do IPPA-R (Gullone e Robinson), assim como com os autores do IPPA original (Armsden e Greenberg), via e-mail, solicitando a devida autorização. Os instrumentos foram traduzidos de inglês para português e, posteriormente, procedeu-se à retroversão para inglês. As versões finais foram avaliadas por diferentes juízes. A versão portuguesa foi utilizada junto de um pequeno grupo de alunos, de ambos os sexos e com idade entre os 9 e 11 anos, a fim de verificar a compreensão dos itens para as crianças. Após obtida a autorização formal dos estabelecimentos de ensino e encarregados de educação procedeu-se à aplicação das escalas, em contexto de sala de aula, no período da manhã de modo a evitar a interferência de factores externos (cansaço ou fome). O tempo gasto pelas crianças variou de grupo para grupo, entre os 25 minutos e os 45 minutos, no máximo. As crianças foram alertadas para o facto de não estarem a ser avaliadas e não existirem respostas certas ou erradas, sendo asseguradas que as análise seriam feitas de modo anónimo.

Os dados foram tratados com a versão 15.0 do SPSS (Statiscal Package for the Social Sciences).

\section{Resultados}

Seguindo o exemplo da estrutura das escalas originais, com três factores (as subescalas Confiança, Comunicação e Alienação (Armsden \& Greenberg, 1987; Gullone \& Robinson, 2005), procedeu-se à análise factorial exploratória das três escalas, para a nossa amostra. Utilizou-se o critério estatístico de inclusão dos itens num factor, tendo em conta o valor mais elevado de saturação, auxiliado pela análise de conteúdo ou significado teórico do item.

A estrutura factorial de cada escala (IPPA-R Pais, IPPA-R Pares e IPPA-R Professores) foi avaliada pela análise factorial exploratória sobre a matriz das correlações, com extracção dos factores pelo método das componentes principais seguida de uma rotação ortogonal tipo varimax, pedindo a extracção de três factores (de modo a manter estrutura idêntica aos estudos originais).

Para averiguar a validade da análise factorial exploratória utilizou-se o critério $\mathrm{KMO}$ (Maroco, 2007), tendo-se obtido um $\mathrm{KMO}=0.856$ para a versão Pais, indi- 
cando uma boa correlação entre as variáveis e o teste de esfericidade de Bartlett com nível de significância associado de $p=.000$ mostrando que existe correlação entre variáveis (Pestana \& Gageiro, 2005); $\mathrm{KMO}=0.928$ na versão Pares, mostrando muito boa correlação entre variáveis, confirmada pelo teste de esfericidade de Bartlett, com significância $p=.000$ justificando a viabilidade de análise factorial; e $\mathrm{KMO}=0.903$ na versão Professores, mostrando igualmente bastante boa correlação entre variáveis, confirmada com o teste esfericidade de Bartlett com nível de significância de $p=.000$. No IPPA-R Pais, os 3 factores resultantes da análise foram explicativos de $40.18 \%$ da variância total (cf. Quadro 1); no IPPA-R Pares, os três factores resultantes explicam $49.30 \%$ da variância total (cf. Quadro 2); e na versão IPPA-R Professores, os 3 factores explicam 45.20\% da variância total (Quadro 3). Os quadros apresentados de seguida apresentam ainda o peso de saturação dos respectivos itens em cada dimensão.

Quadro 1. Factores da Escala de Vinculação aos Pais (IPPA-R, Pais) e saturação dos respectivos itens.

\begin{tabular}{|c|c|c|c|c|}
\hline Factor 1 - “Comunicação e Proximidade Afectiva” & F1 & $F_{2}$ & $F_{3}$ & $\begin{array}{l}\text { Estudo } \\
\text { Original }\end{array}$ \\
\hline $\begin{array}{l}\text { 19. Os meus pais ajudam-me a falar das minhas preocu- } \\
\text { pações. }\end{array}$ & .724 & & & 2 \\
\hline $\begin{array}{l}\text { 16. Eu conto aos meus pais os meus problemas e preocu- } \\
\text { pações }\end{array}$ & .721 & & & 2 \\
\hline $\begin{array}{l}\text { 5. Eu gosto de pedir a opinião dos meus pais acerca das } \\
\text { coisas que me preocupam. }\end{array}$ & .615 & & & 2 \\
\hline $\begin{array}{l}\text { 21. Quando estou zangado com alguma coisa, os meus } \\
\text { pais procuram ser compreensivos. }\end{array}$ & .598 & & & 1 \\
\hline 13. Os meus pais confiam nas minhas decisões. & .593 & & & 1 \\
\hline 15. Os meus pais ajudam-me a compreender-me melhor. & .591 & & & 2 \\
\hline $\begin{array}{l}\text { 12. Quando conversamos sobre algum assunto, os meus } \\
\text { pais valorizam a minha opinião. }\end{array}$ & .554 & & & 1 \\
\hline 20. Os meus pais compreendem-me. & .549 & & & 1 \\
\hline $\begin{array}{l}\text { 25. Se os meus pais sabem que algo me está a preocupar, } \\
\text { eles perguntam-me o que se passa. }\end{array}$ & .532 & & & 2 \\
\hline 1. Os meus pais respeitam os meus sentimentos. & .528 & & & 1 \\
\hline $\begin{array}{l}\text { 24. Eu posso contar com os meus pais quando preciso de } \\
\text { desabafar. }\end{array}$ & .496 & & & 2 \\
\hline $\begin{array}{l}\text { 7. Os meus pais conseguem notar quando estou preocu- } \\
\text { pado com alguma coisa. }\end{array}$ & .484 & & & 2 \\
\hline Factor 2 - “Aceitação mútua e Compreensão" & $\mathrm{F}_{1}$ & $\mathrm{~F}_{2}$ & $\mathrm{~F}_{3}$ & $\begin{array}{l}\text { Estudo } \\
\text { Original }\end{array}$ \\
\hline${ }^{*}$ 3. Eu gostava de ter outros pais. & & .795 & & 1 \\
\hline 2. Penso que os meus pais são uns bons pais. & & .652 & & 1 \\
\hline * 17. Eu sinto-me zangado com os meus pais. & & .626 & & 3 \\
\hline 4. Os meus pais aceitam-me tal como eu sou. & & .571 & & 1 \\
\hline * 10. Irrito-me facilmente com os meus pais. & & .515 & & 3 \\
\hline 22. Eu confio nos meus pais. & & .495 & & 1 \\
\hline
\end{tabular}


Factor 3 - "Afastamento e Rejeição"

23. Os meus pais não entendem o que estou a passar agora.

6. Não vale a pena mostrar os meus sentimentos junto dos meus pais.

18. Eu não recebo muita atenção dos meus pais.

9. Os meus pais esperam demasiado de mim.

8. Eu sinto-me envergonhado ou ridículo quando falo dos meus problemas com os meus pais.

14. Os meus pais já têm os seus problemas, por isso eu não os incomodo com os meus.

11. Eu fico irritado mais vezes do que os meus pais dão conta.

Escala de Vinculação aos Pais

Eighenvalues

\% Variância Explicada

\% Total de Variância Explicada

* Itens cotados inversamente

\begin{tabular}{|c|c|c|c|}
\hline \multirow[t]{2}{*}{$\mathrm{F} 1$} & \multirow[t]{2}{*}{$F_{2}$} & $F_{3}$ & $\begin{array}{l}\text { Estudo } \\
\text { Original }\end{array}$ \\
\hline & & .607 & 3 \\
\hline & & .605 & 2 \\
\hline & & .526 & 3 \\
\hline & & .479 & 1 \\
\hline & & .456 & 3 \\
\hline & & .431 & 2 \\
\hline & & .396 & 3 \\
\hline $\mathrm{F} 1$ & $\mathrm{~F}_{2}$ & $F_{3}$ & Total \\
\hline 6.566 & 1.875 & 1.603 & \\
\hline 26.3 & 7.5 & 6.4 & \\
\hline
\end{tabular}

Quadro 2. Factores da Escala de Vinculação aos Pares (IPPA-R, Pares) e saturação dos respectivos itens

\begin{tabular}{|c|c|c|c|c|}
\hline Factor 1 - "Comunicação e Proximidade Afectiva" & $\mathrm{F} 1$ & F2 & $\mathrm{F}_{3}$ & $\begin{array}{l}\text { Estudo } \\
\text { Original }\end{array}$ \\
\hline $\begin{array}{l}\text { 16. Os meus amigos ajudam-me a compreender-me } \\
\text { melhor. }\end{array}$ & .760 & & & 2 \\
\hline $\begin{array}{l}\text { 2. Os meus amigos conseguem notar quando estou } \\
\text { preocupado com alguma coisa. }\end{array}$ & .741 & & & 2 \\
\hline $\begin{array}{l}\text { 7. Os meus amigos ajudam-me a falar das minhas } \\
\text { preocupações. }\end{array}$ & .740 & & & 2 \\
\hline $\begin{array}{l}\text { 1. Eu gosto de pedir opinião aos meus amigos acerca } \\
\text { das coisas que me preocupam. }\end{array}$ & .730 & & & 2 \\
\hline $\begin{array}{l}25 \text { Se os meus amigos sabem que algo me está a } \\
\text { preocupar, eles perguntam-me o que se passa. }\end{array}$ & .707 & & & 2 \\
\hline $\begin{array}{l}\text { 24. Eu posso falar com os meus amigos acerca dos } \\
\text { meus problemas e preocupações. }\end{array}$ & .684 & & & 2 \\
\hline 17. Os meus amigos preocupam-se com o que eu sinto. & .658 & & & 2 \\
\hline $\begin{array}{l}\text { 15. Quando me sinto zangado com alguma coisa, os } \\
\text { meus amigos procuram ser compreensivos. }\end{array}$ & .656 & & & 1 \\
\hline $\begin{array}{l}\text { 19. Eu posso contar com os meus amigos quando } \\
\text { preciso de desabafar. }\end{array}$ & .572 & & & 1 \\
\hline 21. Os meus amigos respeitam os meus sentimentos. & .529 & & & 1 \\
\hline 12. Os meus amigos escutam o que eu tenho para dizer. & .501 & & & 1 \\
\hline
\end{tabular}


Factor 2 - "Aceitação mútua e Compreensão"

13. Eu sinto que os meus amigos são bons amigos.

20. Eu confio nos meus amigos.

6. Os meus amigos compreendem-me.

14. Sinto facilidade em falar com os meus amigos.

3. Quando conversamos sobre algum assunto, os meus amigos valorizam a minha opinião.

* 5 . Eu gostava de ter outros amigos.

*10. Os meus amigos não entendem o que eu estou a passar agora.

8. Os meus amigos aceitam-me tal como eu sou.

9. Eu sinto necessidade de estar em contacto com os meus amigos mais vezes.

Factor 3 - "Afastamento e Rejeição"

23. Parece que os meus amigos estão zangados comigo sem razão.

22. Eu fico irritado mais vezes do que os meus amigos dão conta.

18. Eu sinto-me zangado com os meus amigos.

4. Eu sinto-me envergonhado ou ridículo quando falo dos meus problemas com os meus amigos.

11. Eu sinto-me sozinho ou à parte quando estou com os meus amigos.

Escala de Vinculação aos Pares

Eighenvalues

\% Variância Explicada

\% Total de Variância Explicada

* Itens cotados inversamente

Quadro 3. Factores da Escala de Vinculação aos Professores (IPPA-R, Professores) e saturação dos respectivos itens

Factor 1 - "Comunicação e Proximidade Afectiva" $\mathrm{F}_{1} \quad \mathrm{~F}_{2} \quad \mathrm{~F}_{3} \quad$ Total

$\begin{array}{lll}8.936 & 1.890 & 1.433\end{array}$

$35.7 \quad 7.6 \quad 5.7$

$.670 \quad 3$

$.524 \quad 3$

$.425 \quad 3$

19. Os meus professores ajudam-me a falar das minhas preocupações. .783

16. Eu conto aos meus professores os meus problemas e preocu- $\quad .768$

pações

5. Eu gosto de pedir a opinião dos meus professores acerca das $\quad .680$

coisas que me preocupam.

24. Eu posso contar com os meus professores quando preciso de $\quad .659$

desabafar.

25. Se os meus professores sabem que algo me está a preocupar, $\quad .654$

eles perguntam-me o que se passa.

7. Os meus professores conseguem notar quando estou preocu- $\quad .602$ pado com alguma coisa.
Estudo

Original

1

1

1

1

2

1

3

1

3

Estudo

Original

$.708 \quad 3$

$678 \quad 3$

3

49.037 
21. Quando estou zangado com alguma coisa, os meus professores $\quad .560$ procuram ser compreensivos.

1. Os meus professores respeitam os meus sentimentos. $\quad .526$

15. Os meus professores ajudam-me a compreender-me melhor. $\quad .522$

Factor 2 - "Aceitação mútua e Compreensão"

2. Penso que os meus professores são uns bons professores.

$\begin{array}{lll}F_{1} & F_{2} & F_{3}\end{array}$

*10. Irrito-me facilmente com os meus professores.
*17. Eu sinto-me zangado com os meus professores.

.733

.622

*3. Eu gostava de ter outros professores.

.608

22. Eu confio nos meus professores.

.607

20. Os meus professores compreendem-me.

.577

.557

12. Quando conversamos sobre algum assunto, os meus profes-

.522

sores valorizam a minha opinião.

13. Os meus professores confiam nas minhas decisões.

4. Os meus professores aceitam-me tal como eu sou.

Factor 3 - "Afastamento e Rejeição"
23. Os meus professores não entendem o que estou a passar agora.

6. Não vale a pena mostrar os meus sentimentos junto dos meus professores.

9. Os meus professores esperam demasiado de mim.

11. Eu fico irritado mais vezes do que os meus professores dão conta.

14. Os meus professores já têm os seus problemas, por isso eu não

os incomodo com os meus.

18. Eu não recebo muita atenção dos meus professores.

8. Eu sinto-me envergonhado ou ridículo quando falo dos meus problemas com os meus professores.

Escala de Vinculação aos Professores

.519

$\mathrm{F}_{1} \quad \mathrm{~F}_{2} \quad \mathrm{~F}_{3}$

.685

.501

Eighenvalues

.494

.473

\% Variância Explicada

\% Total de Variância Explicada 45.181

* Itens cotados inversamente

Para averiguar a fidelidade das escalas de Vinculação aos Pais, Pares e Professores, procedeu-se à análise de consistência interna, determinando o alpha de Cronbach, bem como valores de coeficientes de partição (Split-Hal) e do coeficiente de Spearman-Brown, para o total de cada uma das escalas e respectivas subescalas (Quadro 4). Também foi determinado a correlação item-total e alpha de Cronbach excluindo o item para cada uma das subescalas dos instrumentos. 
Quadro 4. - Consistência interna IPPA-R Pais, Pares e Professores e subescalas

\begin{tabular}{|c|c|c|c|c|}
\hline $\begin{array}{l}\text { Escala de Vinculação aos } \\
\text { Pais - Subescalas }\end{array}$ & $\begin{array}{l}\mathrm{N}^{\circ} \\
\text { Itens }\end{array}$ & $\begin{array}{l}\text { Alpha de } \\
\text { Cronbach }\end{array}$ & $\begin{array}{l}\text { Coeficiente de } \\
\text { Bipartição(Split-half) }\end{array}$ & $\begin{array}{l}\text { Coeficiente de } \\
\text { Spearman-Brown }\end{array}$ \\
\hline $\begin{array}{l}\text { Comunicação e Proximi- } \\
\text { dade Afectiva }\end{array}$ & 12 & .859 & .840 & .845 \\
\hline $\begin{array}{l}\text { Aceitação mútua e Com- } \\
\text { preensão }\end{array}$ & 6 & .695 & .672 & .698 \\
\hline Afastamento e Rejeição & 7 & .567 & .544 & .550 \\
\hline Índice Total da Escala & 25 & .828 & .843 & .843 \\
\hline $\begin{array}{l}\text { Escala de Vinculação aos } \\
\text { Pares - Subescalas }\end{array}$ & $\begin{array}{l}\mathrm{N}^{\circ} \\
\text { Itens }\end{array}$ & $\begin{array}{l}\text { Alpha de } \\
\text { Cronbach }\end{array}$ & $\begin{array}{l}\text { Coeficiente de } \\
\text { Bipartição(Split-half) }\end{array}$ & $\begin{array}{l}\text { Coeficiente de } \\
\text { Spearman-Brown }\end{array}$ \\
\hline $\begin{array}{l}\text { Comunicação e Proximi- } \\
\text { dade Afectiva }\end{array}$ & 11 & .907 & .891 & .903 \\
\hline $\begin{array}{l}\text { Aceitação mútua e Com- } \\
\text { preensão }\end{array}$ & 9 & .783 & .760 & .772 \\
\hline Afastamento e Rejeição & 5 & .640 & .627 & .641 \\
\hline Índice Total da Escala & 25 & .908 & .910 & .910 \\
\hline $\begin{array}{l}\text { Escala de Vinculação aos } \\
\text { Professores - Subescalas }\end{array}$ & $\begin{array}{l}\text { No } \\
\text { Itens }\end{array}$ & $\begin{array}{l}\text { Alpha de } \\
\text { Cronbach }\end{array}$ & $\begin{array}{l}\text { Coeficiente de } \\
\text { Bipartição(Split-half) }\end{array}$ & $\begin{array}{l}\text { Coeficiente de } \\
\text { Spearman-Brown }\end{array}$ \\
\hline $\begin{array}{l}\text { Comunicação e Proximi- } \\
\text { dade Afectiva }\end{array}$ & 9 & .864 & .863 & .864 \\
\hline $\begin{array}{l}\text { Aceitação mútua e Com- } \\
\text { preensão }\end{array}$ & 9 & .831 & .863 & .865 \\
\hline Afastamento e Rejeição & 7 & .547 & .536 & .546 \\
\hline Índice Total da Escala & 25 & .869 & .852 & .853 \\
\hline
\end{tabular}

Quadro 5. - Médias, desvios-padrão, correlação item-total e alphas de Cronbach excluindo o item para as subescalas do IPPA-R Pais

\begin{tabular}{llllll}
\hline Subescalas & Itens & $\begin{array}{l}\text { Média (Desvio } \\
\text { Padrão) }\end{array}$ & $\begin{array}{l}\text { Alpha de } \\
\text { Cronbach }\end{array}$ & $\begin{array}{l}\text { Correlação } \\
\text { Item-Total }\end{array}$ & $\begin{array}{l}\text { Alpha de Cronbach } \\
\text { excluindo o item }\end{array}$ \\
\hline & 1 & $4.38(0.82)$ & .547 & .848 \\
& 5 & $4.19(0.97)$ & .463 & .853 \\
& 7 & $4.39(0.92)$ & .333 & .861 \\
& 12 & $4.12(1.08)$ & .516 & .850 \\
Comunicação & 13 & $4.17(0.96)$ & .572 & .846 \\
e Proximidade & 15 & $4.66(0.69)$ & .859 & .530 & .850 \\
Afectiva & 16 & $4.08(1.07)$ & & .580 & .845 \\
& 19 & $4.15(1.08)$ & .653 & .839 \\
& 20 & $4.55(0.79)$ & & .611 & .844 \\
& 21 & $4.43(0.86)$ & & .610 & .843 \\
& 24 & $4.48(1.01)$ & .517 & .850 \\
& 25 & $4.58(0.75)$ & & .567 & .847 \\
\hline & & & & \\
& & $4.82(0.53)$ & & .566 & .635 \\
& 3 & $4.90(0.45)$ & & .610 & .639
\end{tabular}




\begin{tabular}{llllll} 
& 4 & $4.67(0.86)$ & .695 & .392 & .666 \\
Aceitação & 10 & $4.11(1.13)$ & & .437 & .667 \\
Mútua e & 17 & $4.40(0.98)$ & & .397 & .670 \\
Compreensão & 22 & $4.74(0.72)$ & & .420 & .657 \\
\hline & & & & & \\
& 6 & $2.02(1.36)$ & & .363 & .501 \\
& 8 & $2.14(1.37)$ & & .279 & .532 \\
Afastamento & 9 & $3.64(1.48)$ & & .218 & .556 \\
e Rejeição & 11 & $2.19(1.31)$ & .567 & .257 & .540 \\
& 14 & $2.85(1.52)$ & & .255 & .543 \\
& 18 & $1.87(1.32)$ & & .314 & .520 \\
& 23 & $2.46(1.52)$ & & .346 & .505 \\
\hline
\end{tabular}

O coeficiente alpha de Cronbach para a totalidade da escala $(a=.83)$ revela uma boa consistência interna da Escala de Vinculação aos Pais (Quadro 4); dados corroborados pelos valores do coeficiente de bipartição (Split-Half) e do coeficiente de Spearman-Brown (.84). Quanto à consistência interna de cada subescala os alphas de Cronbach, entre .57 e .86, indicam solidez e fidelidade que vai do aceitável ao bom (Pestana \& Gageiro, 2005).

Todos os itens se correlacionam acima de .20 com a sua respectiva subescala (Quadro 5), cumprindo os critérios de Streiner e Norman (1995). Cumprindo o critério mais exigente de Cohen (1992) ou de Kline (1995), verifica-se que, excepto quatro itens da subescala "Afastamento e Rejeição", todos os outros se correlacionam acima de .30. Os dados são indicadores de uma boa homogeneidade da Escala de Vinculação aos Pais (Streiner \& Norman, 1995).

Quadro 6. - Médias, desvios-padrão, correlação item-total e alphas de Cronbach excluindo o item para as subescalas do IPPA-R Pares

\begin{tabular}{llllll}
\hline Subescalas & Itens & $\begin{array}{l}\text { Média (Desvio } \\
\text { Padrão) }\end{array}$ & $\begin{array}{l}\text { Alpha de } \\
\text { Cronbach }\end{array}$ & $\begin{array}{l}\text { Correlação } \\
\text { Item-Total }\end{array}$ & $\begin{array}{l}\text { Alpha de Cronbach } \\
\text { excluindo o item }\end{array}$ \\
\hline & 1 & $3.63(1.24)$ & & .670 & .898 \\
& 2 & $3.49(1.33)$ & .575 & .904 \\
& 7 & $3.55(1.26)$ & .714 & .895 \\
& 12 & $4.02(1.07)$ & .582 & .902 \\
Comunicação & 15 & $3.65(1.23)$ & & .641 & .899 \\
e Proximidade & 16 & $3.70(1.19)$ & .907 & .711 & .896 \\
Afectiva & 17 & $3.65(1.11)$ & & .650 & .899 \\
& 19 & $3.89(1.16)$ & & .636 & .900 \\
& 21 & $3.89(1.09)$ & & .596 & .902 \\
& 24 & $3.70(1.27)$ & & .685 & .897 \\
& 25 & $3.96(1.17)$ & & .708 & .896 \\
& & & & & \\
\hline
\end{tabular}




\begin{tabular}{llllll}
\hline & 3 & $3.76(1.12)$ & .543 & .753 \\
& 5 & $4.03(1.49)$ & .413 & .775 \\
& 6 & $3.88(1.13)$ & .693 & .731 \\
Aceitação & 8 & $4.32(1.06)$ & .477 & .762 \\
Mútua e Com- & 9 & $3.81(1.26)$ & .783 & .206 & .800 \\
preensão & 10 & $3.44(1.33)$ & & .198 & .804 \\
& 13 & $4.41(0.98)$ & .669 & .740 \\
& 14 & $4.05(1.09)$ & .562 & .751 \\
& 20 & $4.20(1.12)$ & .647 & .738 \\
\hline & & & & .369 & .600 \\
Afastamento e & 11 & $2.44(1.38)$ & & .644 \\
Rejeição & 18 & $1.98(1.09)$ & .640 & .490 & .551 \\
& 22 & $2.73(1.41)$ & & .380 & .595 \\
& 23 & $2.30(1.33)$ & & .483 & .542 \\
\hline
\end{tabular}

O grau de consistência e fidelidade da escala revelou-se muito bom, na sua totalidade, com um alpha de Cronbach de .91 e um coeficiente de bipartição e coeficiente de Spearman-Brown de .91 (Quadro 4). A consistência interna de cada subescala - índices entre .64 e .91- sugerem que se trata de um instrumento sólido e consistente (Pestana \& gageiro, 2005).

No que se refere à análise da consistência de cada um dos itens (Quadro 6), verifica-se que a sua maioria se correlaciona acima de .40 com a respectiva subescala, indicando boa homogeneidade dos factores (Streiner \& Norman, 1995); os restantes itens correlacionam-se entre .20 e .30, cumprindo os critérios de Cohen (1992) e Streiner e Norman (1995). De modo geral, os dados são indicadores de uma boa homogeneidade da Escala de Vinculação aos Pares (IPPA-R Pares). 
Quadro 7. - Médias, desvios-padrão, correlação item-total e alphas de Cronbach excluindo o item para as subescalas do IPPA-R Professores

\begin{tabular}{|c|c|c|c|c|c|}
\hline Subescalas & Itens & $\begin{array}{l}\text { Média (Desvio } \\
\text { Padrão) }\end{array}$ & $\begin{array}{l}\text { Alpha de } \\
\text { Cronbach }\end{array}$ & $\begin{array}{l}\text { Correlação } \\
\text { Item-Total }\end{array}$ & $\begin{array}{l}\text { Alpha de Cronbach } \\
\text { excluindo o item }\end{array}$ \\
\hline \multirow{9}{*}{$\begin{array}{l}\text { Comunicação } \\
\text { e Proximidade } \\
\text { Afectiva }\end{array}$} & 1 & $4.24(1.06)$ & \multirow{9}{*}{.864} & .572 & .852 \\
\hline & 5 & $3.41(1.38)$ & & .560 & .853 \\
\hline & 7 & $3.74(1.02)$ & & .527 & .856 \\
\hline & 15 & $4.28(1.08)$ & & .547 & .854 \\
\hline & 16 & $2.70(1.41)$ & & .598 & .850 \\
\hline & 19 & $3.21(1.40)$ & & .682 & .841 \\
\hline & 21 & $3.83(1.19)$ & & .629 & .847 \\
\hline & 24 & $3.39(1.48)$ & & .619 & .848 \\
\hline & 25 & $3.82(1.24)$ & & .634 & .846 \\
\hline \multirow{9}{*}{$\begin{array}{l}\text { Aceitação } \\
\text { Mútua e } \\
\text { Compreensão }\end{array}$} & 2 & 4.70 (0.69) & \multirow{9}{*}{.831} & .636 & .811 \\
\hline & 3 & $4.32(1.18)$ & & .480 & .822 \\
\hline & 4 & $4.47(0.97)$ & & .453 & .823 \\
\hline & 10 & $4.30(1.10)$ & & .532 & .815 \\
\hline & 12 & $4.00(1.08)$ & & .577 & .810 \\
\hline & 13 & $3.91(1.13)$ & & .547 & .813 \\
\hline & 17 & $4.24(1.19)$ & & .525 & .816 \\
\hline & 20 & $4.03(1.08)$ & & .595 & .807 \\
\hline & 22 & $4.43(0.98)$ & & .579 & .810 \\
\hline \multirow{7}{*}{$\begin{array}{l}\text { Afastamento } \\
\text { e Rejeição }\end{array}$} & 6 & $2.63(1.48)$ & \multirow{7}{*}{.547} & .299 & .499 \\
\hline & 8 & $2.87(1.45)$ & & .251 & .518 \\
\hline & 9 & $3.48(1.45)$ & & .216 & .531 \\
\hline & 11 & $2.39(1.40)$ & & .356 & .477 \\
\hline & 14 & $3.18(1.54)$ & & .139 & .563 \\
\hline & 18 & $2.28(1.42)$ & & .283 & .505 \\
\hline & 23 & $2.71(1.44)$ & & .393 & .461 \\
\hline
\end{tabular}

O alpha de Cronbach de .87 (Quadro 4) indica boa consistência interna da Escala de Vinculação aos Professores (IPPA-R Professores), tendo o grau de fidelidade e solidez da escala sido confirmado pelo coeficiente de bipartição (.85) e de Spearman-Brown (.85) (Quadro4).

Quanto à consistência interna dos itens (por escala), todos os que constituem as subescalas "Comunicação e Proximidade Afectiva" e "Aceitação Mútua e Compreensão", se correlacionam acima de .40 com a respectiva subescala (Quadro 7), indicando boa homogeneidade destes dois factores ou subescalas. Quanto à 
subescala "Afastamento e Rejeição", todos os itens, excepto o 14, se correlacionam acima de .20, cumprindo os critérios de Streiner e Norman (1995).

\section{Conclusões}

O IPPA de Armsden e Greenberg (1987) tem sido um instrumento muito usado na avaliação da representação da vinculação aos pais, particularmente ao longo da adolescência, e que tem revelado boas qualidades psicométricas (cf. Mikulincer \& Shaver, 2007); também estudos com adolescentes portugueses têm recorrido ao IPPA, com resultados psicométricos consistentes (Machado \& Fonseca, 2009; Machado \& Oliveira, 2007; Cunha, 2005, entre outros). Adaptações para idades mais novas, como no estudo de Gullone e Robinson (2005), parecem fazer todo o sentido, reforçado pelas boas características psicométricas encontradas. Considerando ainda que, ao longo do ensino básico os pares e professores ganham um novo relevo na adaptação (ou desequilíbrio) da criança ao meio escolar, podendo tornar-se figuras secundárias vinculativas (Kerns, 2008; Mayseless, 2005; Thompson, 2008), as versões IPPA-R Pares e a construção de uma nova versão IPPA-R Professores parecem justificadas pelo desenvolvimento da teoria da vinculação (Grossmann et al., 2005; Marcus \& Sanders-Reio, 2001; Soares, 2007).

Na globalidade, os resultados deste estudo sugerem que as três versões IPPA- $R$ Pais, Pares e Professores, a presentam boas características psicométricas, os índices de consistência interna das três escalas e respectivas sub-escalas apontam para que se tratam de instrumentos fiáveis, pelo que seria interessante alargar a sua aplicação a outras amostras. No que se refere à validade, as três escalas (e sub-escalas) correlacionam-se de forma significativa entre si, avaliando o mesmo constructo (Figueiredo \& Machado, 2010). A aplicação a estas idades, 9-11 anos, parece interessante, nomeadamente na possibilidade de avaliar a influência da vinculação aos pais na construção de vinculação a figuras relacionais - que se assumem como significativas - em contexto escolar (Pares e Professores) e, particularmente, numa nova fase de estudos em que se multiplicam as matérias curriculares e professores, gerando-se novas exigências de adaptação.

\section{Referências Bibliográficas}

Ainsworth, M., Blehar, M., \& Wall, S. (1978). Patterns of attachment: A psychological study of the Strange Situation. New York: Lawrence Erlbaum Associ.

Allen, J. P., \& Land, D. (1999). Attachment in adolescence. In J. Cassidy, \& P. R. Shaver (Eds.), Handbook of Attachment. Theory, research, and clinical applications, (pp. 319-335). New York: Guilford Press. 
Bowlby, J. (1956). The growth of independence in the young child. Royal Society of Health Journal, 76, 587-591. Retirado de www.psychology.sunysb.edu/attachment/online/ independence.pdf

Bowlby, J. (1998). Separação, angústia e raiva - vol. 2, Apego e perda. São Paulo: Martins Fontes [ed. original ingl., 1973].

Bradley, S. J. (2003). Affect regulation and the development of psychopathology. New York: Guilford Press.

Bretherton, I. (2005). In pursuit of the internal working model construct and its relevance to attachment relationships. In K. E. Grossmann, K. Grossmann, \& E. Waters (Eds.) Attachment from infancy to adulthood. The major longitudinal studies (pp. 13-47). New York: Guilford Press.

Cassidy, J., Scolton, K. L., Krish, S. J., \& Parke, R. D. (1996). Attachment and representations of peer relationships. Developmental Psychology, 32 (5), 892-904.

Cunha, M. (2005). Ansiedade social na adolescência: Avaliação e trajectórias de desenvolvimento. Dissertação de Doutoramento, não publicada. FPCE: Universidade de Coimbra.

Figueiredo, T. \& Machado, T. S. (2010). Representação da vinculação a Pais, Pares e Professores - estudos preliminares do IPPA-R para crianças do ensino básico. Actas do I Seminário Internacional "Contributos da Psicologia em Contextos Educativos" (pp. 1384-1398). Braga: Univ. Minho.

Greenberg, M. T., Kusche, C. A., \& Speltz, M. (1991). Emotional regulation, self-control, and psychopathology: The role of relationships in early childhood. In D. Cicchetti, \& S. L. Toth (Eds.), Internalizing and externalizing expressions of dysfunction. "Rochester Symposium on Developmental Psychopathology”, vol. 2 (pp. 21-55). N. J.: Lawrence Erlbaum Assoc

Grossmann, K., Grossmann, K. E., \& Kindler, H. (2005). Early care and the roots of attachment and partnership representations: The Bielefeld and Regensburg longitudinal studies. In K. E. Grossmann, K. Grossmann, \& E. Waters (Eds.), Attachment from infancy to adulthood. The major longitudinal studies (pp. 117-158). New York: Guilford Press.

Grossmann, K. E., Grossmann, K., \& Waters, E. (2005). Attachment from infancy to adulthood. The major longitudinal studies. New York: Guilford Press.

Gullone, E., \& Robinson, K. (2005). The Inventory of Parent and Peer Attachment-Revised (IPPA-R) for children: A psychometric investigation. Clinical Psychology and Psychotherapy, 12, 67-79.

Gullone, E., Ollendick, T. H., \& King, N. J. (2006). The role of attachment representations in the relationship between depressive symptomatology and social withdrawal in middle childhood. Journal of Child and Family Studies, 15 (3), 271-285.

Karen, R. (1998). Les stratégies de défenses et les possibilités de changement des enfants ayant une forme d'attachement anxieux. Enfance, 3, 28-43.

Kerns, K. A. (2008). Attachment in middle childhood. In J. Cassidy, \& P. R. Shaver (Eds.), Handbook of Attachment. Theory, research, and clinical applications (pp. 366-382). $2^{\text {th }}$ ed., New York: Guilford Press.

Kobak, R., \& Madsen, S. (2008). Disruptions in attachment bonds. Implications for theory, research, and clinical intervention. In J. Cassidy, \& P. R. Shaver (Eds.), Handbook of Attachment. Theory, research, and clinical applications, (pp. 23-47), $2^{\text {th }}$ ed., New York: Guilford Press.

Machado, T. S. (2007). Padrões de vinculação aos pais em adolescentes e jovens adultos e adaptação à Universidade. Revista Portuguesa de Pedagogia, 41 (2), 5-28. 
Machado, T. S. (2009). Vinculação aos pais: retorno às origens. Psicologia, Educação e Cultura, XIII (1), 139-156.

Machado, T. S., \& Fonseca, A. C. (2009). Desenvolvimento adaptativo em jovens portugueses: Será significativa a relação com os pais? INFAD Revista de Psicologia, 1 (3), 461-468.

Machado, T. S., \& Oliveira, M. (2007). Vinculação aos pais em adolescentes portugueses: 0 estudo de Coimbra. Psicologia e Educação, VI (1), 97-115.

Marcus, R. F., \& Sanders-Reio, J. (2001). The influence of attachment on school completion. School Psychology Quarterly, 16 (4), 427-444.

Mayseless, O. (2005). Ontogeny of attachment in middle childhood: Conceptualization of normative changes. In K. A. Kerns, \& R. A. Richardson (Eds.), Attachment in middle childhood (pp.1-23). New York: Guilford Press.

Mendonça, J. S., Cossette, L., Lapointe, M.-N., \& Strayer, F. F. (2008). Vers une analyse systématique des liens d'attachement. Bulletin de Psychologie, 61 (3), 257-266.

Pestana, M., \& Gageiro, J. (2005). Análise de dados para ciências sociais - a complementaridade do SPSS. Lisboa : Sílabo.

Piaget, J. (1986). O nascimento da inteligência na criança. Lisboa: Dom Quixote (1 $1^{\mathrm{a}}$ ed. original, 1936).

Rholes, W. S., \& Simpson, J. A. (2004). Attachment theory. Basic concepts and contemporary questions. In W. S. Rholes \& J. A. Simpson (Eds.), Adult attachment. Theory, research, and clinical implications (pp.3-14). New Yok: Guilford Press.

Soares, I., Martins, E. C., \& Tereno, S. (2007). Vinculação na infância. In I. Soares (Coord.), Relações de vinculação ao longo do desenvolvimento: Teoria e avaliação (pp.47-98). Braga: Psiquilibrios.

Strecht, P. (2008). A minha escola não é esta. Dificuldades de aprendizagem e comportamento em crianças e adolescentes. Lisboa: Assírio \& Alvim.

Streiner, D. L., \& Norman, G. (1995). Health measurement scales: A practical guide to their development and use (2th ed.) Oxford: Univ. Press.

Thompson, R. A. (2008). Early attachment and later development. In J. Cassidy, \& P. R. Shaver (Eds.), Handbook of Attachment. Theory, research, and clinical applications (pp. 348365). $2^{\text {th }}$ ed., New York: Guilford Press.

\section{Attachment to Parents, Peers and Teachers - studies with IPPA-R for children}

The middle childhood period - the latency - has been less invested in attachment studies. However, normative developmental tasks, such us adaptation to school, are essential and appear to require skills that are influenced by attachment to caregivers. At school, peers and teachers may also take significant roles - complementary to parents - functioning there as a significant figure or support. This paper presents preliminary data from the adaptation and validation of three versions - Parents, Peer and Teachers - of IPPA-R (Inventory of Parent and Peer Attachment) - for children aged 9 to 11 years old. The three self-report (each with 25 items) were used in a sample of 245 children from public and private/cooperative schools and data 
suggest a similar structure to each scale. The psychometric qualities found and the ease of application suggests that these are appropriate instruments to evaluate the perception of attachment security of significant people (like parents, peers or teachers) at these ages.

KEY-WORDS: attachment, IPPA (Parent, Peer, Teachers), children.

\section{Attachement aux Parents, Pairs et Professeurs - études avec l'IPPA-R pour enfants}

La période de la moyenne enfance - la latence - a été la moins étudiée dans le champ des investigations sur l'attachement. Toutefois, cette période du développement implique des tâches développementales spécifiques, telles que l'adaptation à un nouveau cours d'études, des tâches qui sont influencées par l'attachement aux parents. A l'école, les pairs et les professeurs peuvent aussi jouer un rôle important - complémentaire à celui des parents - agissant en tant que figures significatives de soutien. Cet article présente les données préliminaires de l'adaptation et validation de trois versions - parents, pairs et enseignants - de l'IPPA-R (Inventory of Parent and Peer Attachment, de Armsden \& Greenberg) - pour des enfants entre 9 et 11 ans. Les trois instruments d'auto-évaluation - chacun avec 25 items - ont été passé a 254 enfants de l'école Public et école Privée/Coopérative; et ils présentent une structure factoriel similaire. Les qualités psychométriques trouvées, et la facilité d'application des questionnaires suggèrent qu'ils sont des outils adéquats pour évaluer la qualité de l'attachement à des figures significatives (e.g. parents, pairs et enseignants) à ces âges.

MOTS-CLÉS: attachement ; IPPA (Parents, Pairs ; Professeurs); enfants 